\title{
Anesthesia and Pain Management: Techniques and Practice
}

\author{
Maurizio Marandola and Alida Albante \\ "Sapienza" University - Policlinico Umberto I, Rome, \\ Italy
}

\section{Introduction}

Surgery for pancreatic cancer (PC) is widely viewed as a complex procedure associated with considerable perioperative morbidity and mortality. Many aspects of surgery for pancreatic cancer, such as the extent of resection, the value of vascular resection, the use of laparoscopy and the importance of treatment at high-volume centers are currently under debate. PC is the fourth leading cause of cancer related mortality in the United States with an estimated 42500 new cases and 35000 deaths from the disease each year (Jemal, 2009). Analysis of overall survival shows that the prognosis of $\mathrm{PC}$ is still quite poor despite the fact that 1-year survival has increased from $15.2 \%$ to $21.6 \%$ and 5 -year survival has increased from 3\% to $5 \%$ (ShaibYH et al., 2006). Surgery is the only chance of cure and the presence of negative resection margins of the primary tumor represent the strongest prognostic factor. Preoperative staging modalities include the combination of several imaging techniques such as computed tomography (CT scan), magnetic resonance imaging (MRI), endoscopic ultrasounds (EUS), staging laparoscopy and laparoscopic ultrasound which aim to identify patients with resectable disease. There is consensus that patients with distant metastases (liver, lung, peritoneum) or local invasion of the surrounding organs (stomach, colon, small bowel) are usually not surgical candidates. A decision analysis demonstrated that the best strategy to assess tumor resectability was based on CT as an initial test and the use of EUS to confirm the results of resectability by CT (Delbecke et al., 1999). Laparoscopic ultrasonography (LUS) has been introduced as an additional procedure to increase the detection of intrahepatic metastases, identify enlarged and suspicious lymph nodes and to evaluate local growth in the vascular structures (Tilleman et al., 2004). The routine use of staging laparoscopy and LUS in patients with radiographically resectable PC remains controversial as imaging modalities has significantly improved, thus reducing the risk of discovering non resectable disease at the time of surgery. Surgery for the PC can be considered an high-risk surgery. This term is rarely explicitly defined in scientific articles. There seems to be a common understanding among surgeons and anesthesiologists of what major surgery means. It can be defined as a surgical procedure that is extensive, involves removal of whole or parts of organs and/or is lifethreatening. It has also been defined as a surgical procedure with $>1$ mortality (Ghaferi et al., 2009). One possibility of evaluating the perioperative risk is the use of 1 of several risk scores. The American Society of Anesthesiologists score is widely used and easy to apply, but excludes age from its risk analysis (Kullavanijaya et al., 2001). Age is securely one of the most important, if not the single most predictive, risk factors for morbidity and mortality after major surgery, including major pancreatic surgery (Riall et al., 2008). 


\section{Preanesthetic considerations}

Patients undergoing pancreatic surgey require a complete history and physical examination. Coexisting medical illnesses may complicate the surgical and anesthetic course. The objectives of the preanesthetic evaluation include establishing a doctor-patient relationship, becoming familiar with the surgical illness and coexisting medical conditions, developing a management strategy for perioperative anesthetic care and obtaining informed consent for the anesthetic plan.

\subsection{History of smoking}

The risk of PC in smokers ranks second to lung cancer and is proportionate to the frequency, duration and cumulative smoking dose (Lynch et al., 2009; Neugut et el., 1995). The patients who smoke have an increased risk of intra- and postoperative complications, particularly of a pulmonary or cardiovascular nature, compared with nonsmoking patients (Bluman et al., 1998; Myles et al., 2002). As carbon monoxide (CO) preferentially binds to hemoglobin in place of oxygen, the short-term effects of cigarette smoking include elevated blood CO levels that result in a $3 \%$ to $12 \%$ reduction of oxygen availability in the periphery (Pearce \& Jones, 1984). Moreover, nicotine stimulates a surgical stress response with increase in heart rate, arterial blood pressure and peripheral vascular resistance. Postoperative pulmonary complications are an important part of the risk of surgery and prolong the hospital stay by an average of one to two weeks. A careful history taking and physical examination are the most important parts of preoperative pulmonary risk assessment. One should seek a history of exercise intolerance, chronic cough or dyspnea. The physical examination may identify

PREOPERATIVE

Encourage cessation of cigarette smoking for at least $8 \mathrm{wk}$

Treat airflow obstruction in patients with chronic obstructive pulmonary disease or asthma

Administer antibiotics and delay surgery if respiratory infection is present

Begin patient education regarding lung-expansion maneuvers

\section{INTRAOPERATIVE}

Limit duration of surgery to less than $3 \mathrm{hr}$

Use spinal or epidural anesthesia

Use laparoscopic procedures when possible

Substitute less ambitious procedure for upper abdominal or thoracic surgery when possible

\section{POSTOPERATIVE}

Use deep-breathing exercises or incentive spirometry

Use continuous positive airway pressure

Use epidural analgesia

Use intercostal nerve blocks

Table 1. Risk-Reduction strategies 
decreased breath sounds, dullness to percussion, wheezes, rhonchi and a prolonged expiratory phase that can predict an increase in the risk of pulmonary complications (Lawrence et al., 1996). The value of routine preoperative pulmonary testing remains controversial. There is consensus that such testing should be performed selectively in patients undergoing no-lung resection. It has been suggested that an increased risk of pulmonary complications is associated with a forced expiratory volume in one second $\left(\mathrm{FEV}_{1}\right)$ or forced vital capacity $(\mathrm{FVC})$ of less than 70 percent of the predicted value or a ratio of $\mathrm{FEV}_{1}$ to $\mathrm{FVC}$ of less than 65 percent (Gass \& Olsen, 1986). A partial pressure of arterial carbon dioxide $\left(\mathrm{PaCO}_{2}\right)$ greater than $45 \mathrm{mmHg}$ can't be considered as a risk factor for pulmonary complications. Several strategies can be adopted in the perioperative period reducing the risks of complications (Table 1).

\subsection{Diabetes}

Nearly $80 \%$ of PC patients have either frank diabetes or impaired glucose tolerance. Diabetes is usually diagnosed either concomitantly or during the two years preceding the diagnosis (Gullo et al. 1994; Permet et al. 1993). The link between abnormal glucose and PC exists only for type II diabetes. Better glycaemic control in diabetic patients undergoing major surgery has been shown to improve perioperative mortality and morbidity. Diabetics are at increased risk of myocardial ischaemia, cerebrovascular infarction and renal ischaemia because of their increased incidence of coronary artery disease, arterial atheroma and renal parenchymal disease. Increased mortality is found in all diabetics undergoing surgery and type I diabetics are particularly at risk of post-operative complications. Increased wound complications are associated with diabetes and anastomotic healing is severely impaired when glycaemic control is poor (Treiman, 1994; Verhofstad \& Hendriks, 1996; Zacharias \& Habib, 1996). Type 2 diabetics not receiving insulin and undergoing minor surgery usually can be managed satisfactory without insulin. However, diabetic patients scheduled for major surgery, who are receiving hypoglicaemic medication or who have poor glycaemic control, should be established on insulin therapy preoperatively. Continuous i.v. infusion of insulin is a better option than intermittent s.c. bolus regimens and may be associated with improved outcome. The immediate perioperative problems facing the diabetic patient are: a) surgical induction of the stress response with catabolic hormone secretion; b) interruption of food intake, which will be prolonged in PC surgery; $c$ ) circulatory disturbances associated with anesthesia and surgery, which may alter the absorption of subcutaneous insulin. Surgery evokes the "stress response", that is the secretion of catecholamines, cortisol, growth hormone and, in some cases, glucagone. These hormones oppose glucose homeostasis, as they have anti-insulin and hyperglicaemic effects. Although diabetics need increased insulin during the perioperative period, requirements for glucose and insulin in this period are unpredictable and close monitoring is essential, especially in the unconscious or sedated patients. The main concern for the anesthetist in the perioperative management of diabetic patients has been the avoidance of harmful hypoglicaemia; mild hyperglicaemia has tended to be seen as acceptable. High-dose opiate anesthetic techniques produce not only haemodinamic, but also hormonal and metabolic stability. Abolition of the catabolic hormonal response to surgery will abolish the hyperglicaemia seen in normal patients and may be of benefit in the diabetic patients. Tight metabolic control in the perioperative period is imperative and is a goal which is attainable in most patients. IV infusion of insulin is the standard therapy for the perioperative management of diabetes, especially in type 1 diabetic patients and patients with type 2 
diabetes undergoing major procedure (Clement et al., 2004). Institutions around the world use a variety of insulin infusion algorithms that can be implemented by nursing staff. Recently, several insulin infusion protocols have been reported in the literature. Two main methods of insulin delivery have been used either combining insulin with glucose and potassium in the same bag (GIK regimen) or giving insulin separately with an infusion pump. The GIK is initiated at a rate of $100 \mathrm{~mL} / \mathrm{h}$ in a solution of $500 \mathrm{~mL}$ of $10 \%$ dextrose, 10 mmol of potassium, and $15 \mathrm{U}$ of insulin. Adjustments in the insulin dose are made in $5 \mathrm{U}$ increments according to blood glucose measurements performed at least every 2 hours. The combined GIK infusion is efficient, safe and effective but does not permit selective adjustment of insulin delivery without changing the bag. Separate continuous glucose and insulin infusions are used more frequently than the glucose-potassium-insulin infusion (Coursin et al., 2004; Furnary et al., 2003; Goldberg et al., 2004; Rehman \& Mohammed, 2003). A proposed regimen for separate IV insulin infusion for perioperative diabetes management is shown in Table 2.

I) Initiating continuous insulin infusion (CII):

Prepare solution: 1 unit (U) per $1 \mathrm{~mL}$ of $0.9 \%$ normal saline.

Start continuous insulin infusion (CII) when blood glucose level $\geq 140 \mathrm{mg} / \mathrm{dL}$ (x 2).

Patients with known diabetes treated with insulin can start CII when blood glucose $\geq 70$ $\mathrm{mg} / \mathrm{dL}$.

Initial rate: divide blood glucose level $(\mathrm{mg} / \mathrm{dL})$ by 100 , then round to nearest $0.5 \mathrm{U}$

II) Insulin infusion rate change:

BloodGlucose $(\mathrm{mg} / \mathrm{dL})$ instructions:

$>200 \quad \uparrow$ rate by $2 \mathrm{U} / \mathrm{h}$

$>160-200 \quad \uparrow$ rate by $1.0 \mathrm{U} / \mathrm{h}$

$>120-160 \quad \uparrow$ rate by $0.5 \mathrm{U} / \mathrm{h}$

80-120 No change in rate

$60-80$ If $<10 \%$ lower blood glucose, rate by $1 \mathrm{U} / \mathrm{h}$,

Check BG within 30 min

If $>10 \%$ lower blood glucose, 2 rate by $50 \%$,

Check BG within 30 min

$<60$ Stop infusion (give IV dextrose $12.5 \mathrm{~g}$ IV bolus),

Check blood glucose within $30 \mathrm{~min}$. When blood glucose $>100 \mathrm{mg} / \mathrm{dL}$, restart infusion at $50 \%$ of previous rate

III) Patient monitoring:

Check capillary blood glucose every hour until it is within goal range for 2 hours, and then decrease to every 2 hours.

Hourly monitoring may be indicated for critically ill patients even if they have stable blood glucose.

If a patient is eating, hourly blood glucose monitoring is necessary for at least 3 hours after eating.

Decrease insulin infusion rate by $50 \%$ if nutritional therapy (e.g. total parenteral nutrition or tube feeds) are discontinued or significantly reduced.

Table 2. Continuous insulin infusion (CII) protocol 


\subsection{Nutritional status}

Malnurished patients who require major operations are predisposed to infectious complications and poor outcome. A low preoperative body mass index (BMI, $\mathrm{kg} / \mathrm{m}^{2}$ ) may be regarded as an overall indicator of the size of the patient's reserves; a BMI $<20 \mathrm{~kg} / \mathrm{m}^{2}$ is an accepted indicator of malnutrition. However, it has been recognized that acutely malnourished patients may still have a normal or even elevated BMI. Serum protein markers such as albumin (for evaluating long-term nutritional status) and prealbumin (for evaluating acute responses to nutritional support) have been shown to be useful additional measurements for assessing nutritional status. Low albumin levels have been identified as an independent risk factor for postoperative morbidity and mortality (Gibbs et al., 1999). It should be emphasized that, although preoperative enteral or parenteral nutritional support clearly benefits surgical cancer patients, a systematic review showed that "preventive" administration of parenteral support in non-malnourished patients did not positively influence outcome and may even be potentially harmful for certain patient subgroups (Koretz et al., 2001). More recently, the concept of immunonutrition has evolved, in which enteral formulas are supplemented with arginine and glutamine, nucleotides or omega-3 fatty acids in an attempt to positively modulate the immune system, but the benefits of immunonutrition remain debatable. Where as perioperative nutrition in the malnourished patient can improve postoperative outcome, immunonutrition seems to attenuate the inflammatory response and interferes with certain immune functions in selected patient groups.

\subsection{Patient with jaundice}

Jaundice results from an abnormally high bilirubin in the blood whose origin may be difficulty in eliminating; it's then an obstructive jaundice. This is the most symptom in patients with periampullary cancer (located near the Vater's ampulla) or cancer of the pancreatic head. It can be considered a risk factor for postoperative complications. $[8,9]$ Many studies demonstrate that it could be associated with a higher incidence of insufficient postoperative renal function, but also of sepsis, haemorrhage, of liver failure and risk of mortality from about $16 \%$ (Jiang \& Puntis, 1997). Jaundice causes a retention of acids and bile salts. In the long term, may cause ascending cholangitis and secondary hepatocellular damage. In case of interruption of bile flow, bile acids and salts can't inhibit the phenomenon of translocation and endotoxemia caused by gram-negative from the digestive tract. These bacteria will then multiply and, for a phenomenon of translocation, can contribute to the dissemination of endotoxins into the systemic circulation then creating a pro-inflammatory state with production of cytokines by activated macrophages and a subsequent risk of multiple organ failure, including the appearance of coagulation disorders. Since surgery in patients with jaundice is thought to increase the risk of postoperative complications, preoperative biliary drainage was introduced to improve the postoperative outcome. In several experimental studies preoperative biliary drainage reduced morbidity and mortality after surgery (Van der Gaag et al., 2009). In a multicentre, randomized trial, Van der Gaag et al compared preoperative biliary drainage with surgery alone for patients with cancer of the pancreatic head and they found that endoscopic preoperative drainage with placement of a plastic stent did not have a beneficial effect on the surgical outcome and early surgery without preoperative drainage did not increase the risk of complications (Van der Gaag, 2010). The preoperative oral administration of bile salts 
or lactulose has been proposed in order to reduce the risk of endotoxemia by blocking bacterial translocation phenomenon from the gut. The effectiveness of this practice has not been validated. Anti-inflammatory and antibiotic prophylaxis should be avoided. In severe cases, a preoperative hemodiafiltration session can address the surgery with more serenity.

\subsection{The general physical examination}

The physical examination should be thorough but focused. Special attention is directed toward evaluation of the airway, heart, lungs and neurologic status.

\subsubsection{Vital signs and head and neck}

Height and wheight are useful in estimating drug dosages and determining volume requirements and the adequacy of perioperative urine output. Ideal body weight should be calculated in obese patients to help determine proper drug dosages and ventilator settings (e.g. tidal volume). Blood pressure should be recorded in both arms and any disparity noted (significant differences may imply disease of the thoracic aorta or its major branches). At same time should be observed and noted the respiration rate and oxygen saturation. One should evaluate maximal mouth opening, the size of the tongue, the ability to visualize the posterior pharyngeal structures and Mallampati classification. A thyromental distance shorter or longer than three fingerbreadth may be a sign of a difficult intubation.

\subsection{Laboratory studies}

A routine laboratory screening tests are necessary to evaluate a recent hematocrit/ hemoglobin level, the platelet activity and the coagulation status before surgery. An ECG should be obtained in any patient with risk factors for coronary artery disease (CAD). It can also detect new dysrhythmias and be useful to evaluate the stability of known abnormal rhythms. A chest radiography should be obtained in all patients to evaluate the cardiovascular image and to document any tracheal deviation or cervical masses.

\section{Anaesthetic management}

General anesthesia with mechanical ventilation is the rule. Spinal anesthesia is impractical owing to the length of the operation. However, epidural analgesia could, in theory, be used as the sole anesthetic technique. It's our belief that the length of surgery, insertion of central lines and the high likelihood of conversion to general anesthesia make epidural alone unsatisfactory. Epidural analgesia may be beneficial post-operatively in reducing venous thromboembolic events, the incidence of respiratory failure and in providing superior analgesia in comparison with opioids. However, there may be clotting abnormalities perioperatively leading to an increased risk of neurological complications. Epidural can make assessment of the patient's volume status more difficult and, with large fluid shifts occurring in this group, a period of hypovolemia could be worsened by concomitant vasodilatation secondary to the epidural analgesia. A balance of these risks needs to be addressed before embarking on an epidural anesthesia technique. It's our practice to routinely use epidural analgesia as a part of combined general and regional technique in these patients. Postoperative analgesia is then provided by a catheter left in place in 
epidural space. The choice of anesthetics must consider the interference pharmacokinetic: benzodiazepines should be avoided for premedication; propofol are the preferred induction agent; morphine should be used with caution in patients with hepatic or renal function (accumulation); muscle relaxants not metabolized by hepatobiliary system (atracurium, cisatracurium) are to be used in the first intent with adequate monitoring. The antibiotic prophilaxis (Enterobacteriaceae and Staphylococcus) is essential in this surgery. Fluid and volume therapy is an important cornerstone of treating critically ill patients in the operating room. New findings concerning the vascular barrier, its physiological functions and its role regarding vascular leakage have lead to a new view of fluid and volume administration. Avoiding hypervolemia, as well as hypovolemia, plays a pivotal role when treating patients both perioperatively and in the intensive care unit. The postoperative phase may be studded with complications: sepsis, hepatic dysfunction, coagulation and metabolic disorders, renal and pulmonary failure and, in addition to the typical risks associated with abdominal surgery, some specific to the Whipple procedure, the two most common are pancreatic fistula and delayed gastric emptying (Buchler et al., 2003). Therefore the recovery in the postanesthesia care unit (PACU) is necessary for these fragile patients.

\subsection{Pharmacology of anesthetics}

\subsubsection{Benzodiazepines}

Pre-, intra-and postoperative use of benzodiazepines (BZP) is widely not recommended because of their hepatic metabolism that exposed to an increased half-life, an extension the duration of action and delayed recovery. In premedication for anxiolysis, with the exception of jaundiced patients, midazolam $0.1-0.4 \mathrm{mg} / \mathrm{Kg}$ is indicated; after i.v. administration, the onset of central nervous system effects occurs in 2 to 3 minutes. BZP enhance inhibitory neurotransmission by increasing the affinity of $\mathrm{GABA}_{\mathrm{A}}$ receptors for GABA . Effects are terminated by redistribution, the metabolism is tipically hepatic and renal the elimination. Administration of a BZP to a patient receveing the anticolvulsivant valproate may precipitate a psychotic episode.

\subsubsection{Induction agents}

Thiopental has no longer the place it has had for very many years. In addition, its use was largely dissuaded in the presence of hepatobiliary disease because of its hepatic metabolism (cytochrome P450). Thiopental is metabolized to pentobarbital, an active metabolite with a longer half- life. Its use therefore exposed to delayed awakening. Similar to propofol, barbiturates facilitate inhibitory neurotransmission by enhancing $\mathrm{GABA}_{\mathrm{A}}$ receptor function. They also inhibit exicitatory neurotransmission via glutamate and nicotinic acetylcholine receptors. Absolutely contraindicated in patient with acute intermittent porphyria, variegate porphyria and hereditary coproporphyria (barbiturates induce porphyrin synthetic enzymes such as $\delta$-aminolevulinic acid synthetase). Ketamine for its variable pharmacokinetics in the presence of extrahepatic biliary obstruction and postoperative hallucinatory effects has a limited use in clinical practice. Propofol is the agent of choice, not only for the induction, but also for sedation in patients requiring postoperative ventilatory support. It has a short action effect and the rapid metabolism is not influenced in the presence of liver failure. It is prepared as a $1 \%$ isotonic oil-in water emulsion, which contains egg lecithin, glycerol and 
soybean oil. Bacterial growth is inhibited by ethylenediaminetetraacetic acid (EDTA), diethylenetriaminepentaacetic acid (DPTA), sulfite, or benzyl alcohol depending on the manufacturer (don't use opened propofol after 6 hours to prevent inadvertent bacterial contamination). Mode of action: facilitation inhibitory neurotransmission by enhancing the function of $\mathrm{GABA}_{\mathrm{A}}$ receptors in the central nervous system; the modulation of glycine receptors, N-etyl-D aspartate receptors, cannabinoid receptors and voltage-gated ion channels may also contribute to propofol's actions. After the infusion it can be observed dose-dependent decreases in preload, afterload and contractility that lead to decrease in blood pressure and cardiac output. Hypotension may be marked in hipovolemic, elderly, or hemodynamically compromised patients. Heart rate is minimally affected and baroreceptor reflex is blunted. Adverse effects are: venous irritation, lipid disorders, myoclonus and hiccups, "propofol infusion syndrome".

\subsubsection{Opioids}

Morphine and its derivatives are essential for the perioperative period (commonly used in general anesthesia) and are frequently used to ensure postoperative analgesia. Opioids, including morphine and fentanyl, have been accused to increase the bile ducts tone and to determine a spasm of Oddi's sphincter. However, the consequences in clinical practice are limited: the pressure is most often in the bile duct within normal limits and the delay of the bile's drainage in the duodenum is not significant. Opioids differ in their potencies, pharmacokinetics and site effects. The mode of action is due to the interaction with specific receptors in the brain, spinal cord and peripheral neurons (Kumamoto et al., 2011). After i.v. administration, the onset of action is within minutes for the fentanyl derivatives; due to their lower lipid solubility hydromorphone and morphine may take from 20 to 30 minutes for their peak effect. Elimination is primarily by the liver and depends on hepatic blood flow. In patients with renal failure, the accumulation of morphine -6- glucuronide, the active metabolite, may cause prolonged narcosis and respiratory depression. Fentanyl is metabolized by hydrolysis and N-dealkylation and its metabolites are excreted in the urine. Function liver in the normal range is necessary to plasma clearance in case of repeated injections. The pharmakocinets of alfentanil is also changed, with a longer duration of action and an initial effect over pronounced. The sufentanil phamacokinetics is not altered even in cases of moderate hepatic insufficiency. The short duration of action of remifentanil (context-insensitive half-time) and especially its extrahepatic metabolism (by non specific esterases in tissues, primarily skeletal muscle) are purely an advantage (Dershwitz et al., 1996). Opioids exert emetogenic effects and represent a significant cause of patient discomfort. Nausea and vomiting can occur because of the direct stimulation of the chemoreceptor trigger zone, of the vestibular apparatus, inhibition of gut motility (Porreca \& Ossipov, 2009).

\subsubsection{Halogenated}

Inhalation agents represent a basic drug used in modern balanced anesthesia. Actually the most important halogenated in the clinical use are sevoflurane and desflurane. They were developed in the late 1960s and tested in clinical practice much later. Sevoflurane was not immediately introduced to the USA because of its fluorine release and its reaction with 
absorbed carbon dioxide. After several years of clinical application, no renal failure was observed and appropriate studies on compound A did not show any renal effects in human. Desflurane is largely appreciated for its high stability. Less than $0.02 \%$ of desflurane is metabolized, thus, plasma fluorine levels are very low. The very low solubility of desflurane allows for a surprisingly rapid emergence from anesthesia. Nitrous oxide has a controversial role in the modern anesthesia. For one and a half centuries it has played a relevant role in general anesthesia. Many of the side effects of nitrous oxide correlate with its physical properties. Its ability to diffuse into air filled cavities increases the likelihood of pneumothorax, air emboli and pressure in the cuff of the endotracheal tube. Nitrous oxide diffusion causes an increase in the middle ear pressure and distension of the bowel, possibly resulting in increases in postoperative nausea and vomiting. The results of a questionnaire proposed by the Association of Anesthesist of Great Britain and Ireland indicate that $49 \%$ of anesthesist had reduced their use of nitrous oxide (Henderson et al., 2002). According to Baum, nitrous oxide should not be used routinely as a carrier gas and the safer mixture of oxygen/medical air is able to replace this old anesthetic with some economical advantages (Baum, 2004). The combination of halogenated agents with short acting opioids results in the possibility of limiting the clinical application of nitrous oxide. Attempts to replace nitrous oxide with other gases has led to an increase in studies on xenon. This inert gas does not undergo metabolic biotransformation and has no direct negative environmental effects. Xenon has a very low solubility in the blood and its potency is higher when compared to nitrous oxide solubility (Hecker et al., 2004). Xenon cannot be synthesized and the available amount is very low. Consequently, at present, the cost of compound may be a limiting factor for the clinical use. The pharmacokinetic advantages of inhalation anesthetics are unique. By increasing or decreasing their inspired concentration, it is possible to increase or decrease their concentration in the blood and tissues, allowing for rapid changes in anesthesia depth and providing a simple method for inducing, maintaining and reversing general anesthesia. The flexibility of inhalation anesthesia cannot be reproduced with modern intravenous hypnotics or opioids. Furthermore, it is important to underline the protective effects of inhalation agents on several different organs.

\subsubsection{Neuromuscolar blocking drugs}

Non depolarizing blockade is produced by reversible competitive antagonism of Ach at the $\alpha$ subunits of the AChRs. The principal pharmacologic effect is to interrupt transmission of synaptic signaling at the neuromuscular junction. The neuromuscular blocking agents in biliary excretion (e.g. vecuronium) should be avoided in favor of those metabolized by way of Hoffman (atracurium, cis-atracurium). In all cases, the use of a monitoring of neuromuscular blockade is obviously essential (Chiu \& White, 2000; Murphy \& Szokol,2004).

\subsection{Monitoring}

Standard monitoring for general anaesthesia involves oxygenation (analyzer and pulse oximetry), ventilation (capnography and minute ventilation), circulation (ECG with STsegment analysis, blood pressure and perfusion assessment) and temperature if necessary. Additional monitoring may be added such as invasive arterial and venous pressure 
monitoring, trans esophageal echocardiography (TEE), neuromuscular blockade and central nervous system monitoring. Automated noninvasive blood pressure is the most common noninvasive method of measuring blood pressure in the operating room for minor surgery. Invasive blood pressure (IBP) monitoring is imperative in the pancreatic surgery; there is potential for rapid swings in blood pressure and acid-base balance often needs managing (acidosis is common). IBP uses an indwelling arterial catheter coupled through fluid-filled tubing to a pressure transducer. The transducer converts pressure into a electrical signal to be displayed. Generally the catheter size is 18 to 20 gauge for adults. The radial artery is the most common site. Other locations include ulnar, brachial, axillary, femoral and dorsal pedis arteries. The procedure should be perfomed aseptically. Local anesthetic may be used to raise a skin wheal if the patient is awake. For catheter insertion it can be used the Seldinger technique. The modified Allen test has been recommended to assess the relative patency and contribution of the radial and ulnar arteries to the blood supply to the hand, but the results are unreliable. Central venous catheter (CVC) is essential; ultrasound guidance can be useful in the patients that have had multiple previous cannulation. The central venous pressure (CVP) and cardiac output (CO) are monitored by CVC. CVP is measured by coupling the intravascular space to a pressure transducer using a fluid-filled tubing. Pressure is monitored at the level of the vena cava or the right atrium. The normal CVP is 2 to $6 \mathrm{mmHg}$. Positive- pressure ventilation affects both cardiac output and venous return. According to the Starling rule, the transmural pressure, which is the difference between the atrial pressure and extracardiac pressure, correlates with the cardiac output. At low level of PEEP, the CVP increases with increased PEEP, at high levels of PEEP (over 15 $\mathrm{cmH}_{2} \mathrm{O}$ ), CVP increases as the cardiac output is depressed because of impaired right ventricular output. Common locations include internal jugular and subclavian vein. Multiple lumen catheters are directly inserted and are available with one to four lumens to provide access for multiple drugs, pressure monitoring and blood sampling. Temperature may be measured continuously; the limitation of more external methods of temperature determination is that they may not reflect changes in the core body temperature, especially in the presence of vasoconstriction. Oropharyngeal temperature monitoring is preferred in any lengthy laparotomy, which has potential for blood loss and perioperative clotting abnormalities. Ventilation is assessed by end- tidal carbon dioxide measurements and spirometry. Capnometry and capnography are often used as synonyms, as both analyze and record carbon dioxide, with the latter including a waveform. Capnography not only evaluates respiration but also confirms of endotracheal intubation and its diagnostic of pathologic conditions. Neuromuscular blockade is utilized, above all for patients with coexisting renal failure. The adductor pollicis response to ulnar nerve stimulation at the wrist is most often used, because it is easily accessible, and the results are not confused with direct muscle activation. Cutaneous electrodes are placed at the wrist over the ulnar nerve and attached to a battery-driven pulse generator, which delivers a graded impulse of electrical current at a specified frequency. For maximal twitch response, the negative pole (active) should be placed distally over the ulnar nerve at the wrist. Evoked muscle tension can be estimated by feeling for thumb adduction or measured by using a force transducer attached to the thumb. After administration of a neuromuscular blocking drug (NMBD), the developed tension and twitch height decrease with the onset of blockade. Foley catheter is 
the rule in all patient ones, necessary for fluid management and the control of the renal functionality.

\subsection{Conduct of anaesthesia}

The primary goals of general anesthesia are to maintain the health of the patient while providing amnesia, hypnosis (lack of awareness), analgesia and immobility. Secondary goals may vary depending on the patient's medical condition and the surgical procedure. Perioperative planning involves the integration of preoperative, intraoperative and postoperative care. Flexibility, the ability to anticipate problems before they occur and the ability to execute contingency plans are skills that define the expert anesthetist. An anesthetic plan developed prior to entering the operating room helps the anesthetist marshal appropriate resources and anticipate potential difficulties. Important elements to consider in the anesthetic plain include: risk assessment (ASA classification), specific homeostatic challenges, intravenous access, monitoring, airway management, medications, perioperative analgesia, postoperative transport and disposition. Preoperative medications is realized with midazolam $0.1-0.4 \mathrm{mg} / \mathrm{Kg}$ (except cases of jaundice) for anxiety control. It is also important to consider aspiration prophylaxis; drugs to neutralize gastric acid and decrease gastric volume are used: metoclopramide $10 \mathrm{mg}$ and ranitidine $50 \mathrm{mg}$ usually. Induction of anesthesia produces an unconscious patient with depressed reflexes who is dependent on the anesthetist for maintenance of homeostatic mechanisms and safety. The patient's position for induction is usually supine, with extremities resting comfortably on padded surface in a neutral anatomic position. The head should rest comfortably on a firm support, which is raised in a "sniff" position. Routine pre-induction administration of oxygen minimizes the risk of hypoxia developing during induction of anesthesia. High flow ( 8 to $10 \mathrm{~L} /$ minute) oxygen should be delivered via a face mask placed gently on the patient's face. Commonly, for the induction of anesthesia, we use propofol $4-6 \mathrm{mg} / \mathrm{Kg}$, a non- depolarizing neuromuscular blocking agent (cis-atracurium $0,15 \mathrm{mg} / \mathrm{Kg}$ is the usual choice) and sufentanil $0.1-0.5 \mathrm{mcg} / \mathrm{Kg}$. Hypertensive patients may have an exaggerated pressor response to laryngoscopy. To obtund this response, opioids or $\beta$-blockers can be used. Tracheal intubation is performed with laryngoscopy usually. An appropriate ETT size depends on the patient's age, body habitus. Proper placement of the ETT needs to be verified by the detection of carbon dioxide in end-tidal or mixed expiratory gas as well as inspection and auscultation of the stomach and both lung fields during positive-pressure ventilation. Tidal volumes of $8-10 \mathrm{ml} / \mathrm{Kg}$ and a respiratory rate of 10 to 12 breaths/minute are set and low level PEEP is beneficial. For the maintenance of anesthesia we use normally a mixture of oxygen and air $(40 \% / 60 \%)$ and an halogenated (sevoflurane or desflurane) with a continuous infusion of sufentanil until the end of operation. The infusion of sufentanil generally is continued in the PACU to better adapt the patient to the mechanical ventilation. If we decide for a blended anesthesia, before the induction of anesthesia, we perform a thoracic epidural anesthesia (T8-T10) with the patient in sitting position.

\subsection{Epidural anaesthesia / analgesia}

The epidural space is surrounded by the outer surface of the dura mater and the bony and ligamentous walls of the spinal canal and extends from the foramen magnum to the sacral hiatus. The cross-sectional area of the epidural space becomes smaller cranially, as the theca 
and its contents tend to occupy a greater proportion of space. Hence, a given volume of drugs affects a greater number of segments the more cranially it is introduced. The epidural space contains nerve roots, fat, spinal arteries and lymphatics, as well as a valveless venous system that communicates directly with both the intracranial sinuses via the basovertebral veins and the general circulation via the azygos vein. Dorsal and ventral spinal nerve roots covered by dura mater pass across the epidural space and drugs within this space can act on any nerve that traverses it - whether it be motor, sensory or autonomic. Epidural analgesics may prevent the release of neurotransmitters from afferent pain fibres, block receptors to neurotransmitters released by primary afferent pain fibres or interrupt the transmission of pain-related information in the dorsal horn of the spinal cord. Drugs introduced into the epidural space also have the potential to pass into the brain and the general circulation depending on their pharmacokinetics. Epidural analgesia was originally achieved with local anaesthetic agents but, more recently, with opioids or a combination of local anaesthetics and opioids. This combination has a synergistic action that allows the concentration of each drug to be reduced, thereby limiting unwanted effect produced by higher concentrations. Ketamine, midazolam or clonidine has also been used in combination with local anaesthetics and opioids to obtain the best intra- and post-operative pain control. Local anaesthetics penetrate axonal membranes within the epidural space and bind to sodium channels in nerves. This inhibits sodium conductance and reduces action potential depolarization, thereby reducing nerve stimulus propagation. The drawback is that the effect is non selective, involving both autonomic and somatic nerves. Thinner nerve fibres are affected by lower local anaesthetic concentrations than thicker fibres, suggesting that neuronal block is a function of diameter. With increasing local anesthetic concentration, the thinner $\mathrm{C}$ fibres (pain and autonomic fibres) are blocked first, followed by B fibres (preganglionic sympathetic fibres) and finally the largest A fibres (touch, pressure sensation and motor fibres). Epidural analgesia aims to produce a differential nerve block, affecting predominantely nociceptive fibres with few motor effects. Opioids act on opioid receptors that are widespread throughout the nervous system, but more concentrated in the medullary dorsal horn of the spinal cord and the periaqueductal grey matter of the brain. Opioid receptors belong to the family of guanine nucleotide-binding protein receptors. They exist as three principle types (OP1, OP2 and OP3) and opioids acting at these receptors have the advantage of selectively blocking pain without affecting motor function or the sense of touch. Epidural opioids act mainly on presynaptic and postsynaptic receptors in the substantia gelatinosa of the dorsal horn of the spinal cord (Fotiadis et al., 2004). The combination of thoracic epidural analgesia (TEA) and general anesthesia has become a widespread anesthetic technique for the perioperative treatment of patients undergoing major abdominal surgery. The neuraxial application of local anesthetics and opioids provides superior pain relief, reduced hormonal and metabolic stress, enhanced normalization of gastrointestinal function and thus a shortened postoperative recovery time, facilitating mobilization and physiotherapy. TEA is currently thought to mitigate this effect by blocking nociceptive afferent nerves and thoracolumbar sympathetic efferent routes. In a very recent cohort study Van Lier F. et al. (Van Lier et al., 2011) demonstrated that epidural analgesia reduces postoperative pneumonia in patients with chronic obstructive pulmonary disease (COPD) undergoing major abdominal surgery. Among the long-acting local anesthetics, the S-enantiomer, ropivacaine, is gaining increasing preference for continuous epidural analgesia. Ropivacaine has lower central nervous system and cardiac toxicity and a less frequent incidence of motor block (differential 
block) during mobilization than bupivacaine (Macias et al., 2002). Panousis et al. evaluated the effect of different epidurally administered concentrations of ropivacaine on inhaled anesthetic, fluid and vasopressor requirement and hemodynamic changes. They concluded that ropivacaine $0.5 \%$ compared with a ropivacaine $0.2 \%$ concentration led to a greater inhaled anesthetic-sparing effect at the same levels of IV fuid supply and vasopressor support (Panousis et al., 2009). In a critical appraisal published on 2008, Pratt WB et al. concluded that although it may provide more effective initial pain control, epidural analgesia does not necessarily improve the critical outcome as after pancreatoduodenectomy. The Authors explained it with the high propensity for rapid fluid shifts and excessive blood loss during this operation, which may negate the proposed benefits of administering analgesic medications by epidural infusion and they reinforced these results considering the frequent need to terminate epidural infusions because of hemodynamic compromise or inadequate analgesia. Spinal epidural hematoma (SHE) after epidural analgesia is a rare but serious complication. Most cases of SHE after epidural block are attributed to a bleeding tendency or anticoagulant therapy. Placement of an epidural catheter may cause SHE more often than expected, but most SEHs remain asymptomatic (Inoue, 2002). The incidence of significant spinal bleeding (paraplegia requiring laminectomy) has been estimated at 1:1,000,000 in patients without clinically apparent coagulation disorders. Vandermeulen et al. found spinal bleeding immediately after removal of the epidural catheter in 15 of the 32 cases that he reviewed. Spontaneous SHE has been reported in a few cases (Skilton, 1998; Vandermeulen, 1994). The maximum incidence of clinically important spinal bleeding after epidural catheter blocks without specific additional risk factors probably list between 1:190,000-200,000. Approximately 60$80 \%$ of all clinically important spinal bleeding is associated with haemostatic disorders or a blood tap. Removal of an epidural catheter should be considered a significant risk factor for spinal bleeding because $30-60 \%$ of clinically important spinal hematomas occurs after catheter removal (Tryba, 1998). A practical approach to the patients with anticoagulant/antiaggregant therapy is reported in Table 3, according to the last guidelines of the European Society of Anaesthesiology.

Where central neural block is contraindicated (e.g systemic sepsis, in anti-coagulated patients), or where epidural catheterization is technically impossible, bilateral paravertebral nerve blocks (PVB) is a suitable alternative. The paravertebral space is a potential space, which is turned into a temporary cavity by fluid. Anaesthesia occurs because of direct penetration of local anesthetic (LA) into the neurological structures contained within the PVB (anterior and posterior ramus of the intercostals nerve, sympathetic chain, rami comunicantes, sinu-vertebral nerve). The spinal nerve, lacking both an epineurvium and part of the perinervium and with only a thin membranous root sheath is easily penetrated by LA and hence easily and efficiently blocked (Karmaker, 2001). We recommend the use of levobupivacaine or ropivacaine for bilateral blocks. Good preservation of postoperative pulmonary function has been demonstrated, particularly in thoracotomy, which is a significant benefit over epidural analgesia (Davies et al., 2006). The incidence of complications such as pneumothorax and hypotension is low. For bilateral PVB a variety of techniques, including loss of resistance, nerve stimulators and ultrasound, have been used. Potential or relative contraindications to the use of PVB are: coagulation disordes, tumor in the PVB and empyema. The relationship of regional anaesthesia to wound healing, chronic postoperative pain, and cancer recurrence rates with this and other block is important. 


\begin{tabular}{|c|c|c|c|}
\hline & $\begin{array}{c}\text { Time before } \\
\text { puncture/catheter } \\
\text { manipulation or } \\
\text { removal }\end{array}$ & $\begin{array}{c}\text { Time after } \\
\text { puncture/catheter } \\
\text { manipulation or } \\
\text { removal } \\
\end{array}$ & Laboratory tests \\
\hline $\begin{array}{l}\text { Unfractionated heparins } \\
\text { (for prophylaxis, } \\
\leq 15000 \text { IU per day) }\end{array}$ & $4-6 \mathrm{~h}$ & $1 \mathrm{~h}$ & $\begin{array}{l}\text { Platelets during } \\
\text { treatment for } \\
\text { more than } 5 \text { days }\end{array}$ \\
\hline $\begin{array}{l}\text { Unfractionated heparins } \\
\text { (for treatment) }\end{array}$ & $\begin{array}{l}\text { i.v. } 4-6 \mathrm{~h} \\
\text { s.c. } 8-12 \mathrm{~h}\end{array}$ & $\begin{array}{l}1 \mathrm{~h} \\
1 \mathrm{~h}\end{array}$ & $\begin{array}{l}\text { aPTT, ACT, } \\
\text { platelets }\end{array}$ \\
\hline $\begin{array}{l}\text { Low-molecular-weight } \\
\text { heparins (for prophylaxis) }\end{array}$ & $12 \mathrm{~h}$ & $4 \mathrm{~h}$ & $\begin{array}{l}\text { Platelets during } \\
\text { treatment for } \\
\text { more than } 5 \text { days }\end{array}$ \\
\hline $\begin{array}{l}\text { Low-molecular-weight } \\
\text { heparins (for treatment) }\end{array}$ & $24 \mathrm{~h}$ & $4 h$ & $\begin{array}{l}\text { Platelets during } \\
\text { treatment for } \\
\text { more than } 5 \text { days }\end{array}$ \\
\hline $\begin{array}{l}\text { Fondaparinux } \\
\text { (for prophylaxis, } \\
2.5 \mathrm{mg} \text { per day) }\end{array}$ & $36-42 \mathrm{~h}$ & $6-12 \mathrm{~h}$ & $\begin{array}{l}\text { (anti-Xa, } \\
\text { standardised for } \\
\text { specific agent) }\end{array}$ \\
\hline $\begin{array}{l}\text { Rivaroxaban (for } \\
\text { prophylaxis, } 10 \mathrm{mg} \text { q.d.) }\end{array}$ & $22-26 \mathrm{~h}$ & $4-6 \mathrm{~h}$ & $\begin{array}{l}\text { (PT, standardised } \\
\text { for specific agent })\end{array}$ \\
\hline $\begin{array}{l}\text { Apixaban (for prophylaxis, } \\
2.5 \mathrm{mg} \text { b.i.d.) }\end{array}$ & $26-30 \mathrm{~h}$ & $4-6 h$ & - \\
\hline $\begin{array}{l}\text { Dabigatran (for } \\
\text { prophylaxis, } 150-220 \mathrm{mg} \text { ) }\end{array}$ & $\begin{array}{l}\text { Contraindicated } \\
\text { according to the } \\
\text { manufacturer }\end{array}$ & $6 \mathrm{~h}$ & $?$ \\
\hline Coumarins & INR $\leq 1.4$ & after catheter removal & INR \\
\hline $\begin{array}{l}\text { Hirudins } \\
\text { (lepirudin, desirudin) }\end{array}$ & $8-10 \mathrm{~h}$ & $2-4 \mathrm{~h}$ & aPTT, ECT \\
\hline Argatrobanc & $4 \mathrm{~h}$ & $2 \mathrm{~h}$ & aPTT, ECT, ACT \\
\hline Acetylsalicylic acid & None & None & \\
\hline Clopidogrel & 7 days & after catheter removal & \\
\hline Ticlopidine & 10 days & after catheter removal & \\
\hline Ticagrelor & 5 days & $\begin{array}{c}6 \mathrm{~h} \text { after catheter } \\
\text { removal }\end{array}$ & \\
\hline Cilostazolc & $42 \mathrm{~h}$ & $\begin{array}{l}5 \mathrm{~h} \text { after catheter } \\
\text { removal }\end{array}$ & \\
\hline Prasugrel & 7-10 days & $\begin{array}{l}6 \mathrm{~h} \text { after catheter } \\
\text { removal }\end{array}$ & \\
\hline NSAIDs & None & None & \\
\hline
\end{tabular}

ACT, activated clotting time; aPTT, activated partial thromboplastin time; b.i.d., twice daily; ECT, ecarin clotting time; INR, international normalised ratio; IU, international unit;

i.v., intravenously; NSAIDs, non-steroidal anti-inflammatory drugs; s.c., subcutaneously; q.d., daily.

All time intervals refer to patients with normal renal function. Prolonged time interval in patients with hepatic insufficiency.

Table 3. Recommended time intervals before and after neuraxial puncture or catheter removal (Gogarten et al., 2010) 


\subsection{Postoperative care}

\subsubsection{Postoperative I.V. analgesia}

In patients with epidural catheter the analgesia can be continued with a volumetric or elastomeric pump with a rate infusion of $5-8 \mathrm{ml} / \mathrm{h}$, by using local anesthetics alone or in combination with opioids. Generally we use ropivacaine $2 \mathrm{mg} / \mathrm{ml}$ and sufentanil $5 \mathrm{mcg} / \mathrm{ml}$. In patients where was impossible the positioning of an epidural catheter the postoperative analgesia is performed with NSAIDs or opioids or mixture of them. Several protocols are reported in literature for IV analgesia, but generally morphine is the leader drug. The patient controlled analgesia (PCA) is the best route of administration with a primary dose of 2-10 $\mathrm{mg}$ and a rescue dose of 0.5-2 mg with a lock-out of 5-10 minutes (Miaskowski, 2005). A specific role have the COX-2 inhibitors. Parecoxib $(40-80 \mathrm{mg})$ is disposable for intravenous administration (Nussmeier et al, 2006).

\subsection{Pain and inoperable pancreatic cancer}

Pancreatic diseases such as cancer can cause clinically significant pain in the upper abdomen, which may radiate to the back. Pain management for pancreatic cancer patients is one of the most important aspects of their care, as it is one of the most weakening symptoms. The best therapy involves adequate therapy with constant assessment. The current management of pancreatic pain follows the WHO three-step ladder for pain control, starting with non-opioid analgesics such as nonsteroidal anti-inflammatory drugs (NSAIDs) and progressing to increasing doses of opioid analgesics (WHO, 2008). For pain that does not respond to drugs, or when oral or topical medication leads to unacceptable side effects such as nausea, constipation, somnolence, confusion, dependence and addiction, an alcohol nerve block can be indicated. This provides pain relief by acting directly on the nerves (celiac plexus) that carry painful stimuli from the diseased pancreas to the brain. Pancreatic cancer causes severe pain in $50 \%$ to $70 \%$ of patients. This kind of pain is multi-factorial (pancreatic duct obstruction and hypertension, neural invasion) and it is often difficult to treat (Staatas 2001). Different mechanisms perpetuate pancreatic pain: infiltration of nerve sheaths and neural ganglia, increased ductal and interstitial pressure and gland inflammation. Pancreatic pain is generally transmitted through the celiac plexus, a neural structure located in the upper abdomen, near the emergence of the celiac trunk from the aorta. Celiac plexus neurolysis was first described by Kappis (1919) and is done at the level of the L1 vertebral body, with the patient in the prone position. There are a number of variations on the technique (Giménez, 1993). It has been described in the literature since the 1950s but the first prospective study was published in 1990 and the first randomized in 1992. Celiac plexus neurolysis can be done surgically under fluoroscopic guidance or under computed tomography (CT) guidance. The target for celiac axis destruction are the splanchnic nerves and/or celiac ganglia. The splanchnic nerves cross the diaphragm, enter the abdominal cavity and form the celiac plexus. The celiac ganglia are located around the celiac artery anterior to the aorta, in varying positions, from T12 to L2. They can be reached percutaneously by different routes, with one needle through the anterior approach (under CT or ultrasound guidance) or with one or two needles through the posterior approach. During abdominal surgical procedures for pancreatic cancer chemical splanchnicectomy can be achieved by injecting the neurolytic solutions directly into the junction area of the splanchnic nerves with the celiac ganglia in the retroperitoneal area. With the advent of 
endoscopic ultrasonography (EUS) new therapeutic applications for endoscopy have been developed and a needle can now be guided safely in the celiac plexus (Puli, 2009). The celiac plexus is destroyed by alcohol injected under the guidance of real-time endosonography. First, using a linear array echo-endoscope, the region of the celiac ganglia is located from the lesser curve of the stomach, following the emergence of the celiac trunk from the aorta. The anterior approach avoids the retro-crural space and minimizes the risk of neurologic complications such as paraesthesia or paralysis. Anyway, although statistical evidence is minimal for the superiority of pain relief over analgesic therapy, the fact that CPB causes fewer adverse effects than opioids is important for patients.

\section{Conclusion}

Pancreatic ductal adenocarcinoma (90\% of pancreatic cancers) remains a devastating disease. For a select group in which complete resection is possible, surgery prolongs survival. Pancreaticoduodenectomy, the "Cadillac" of abdominal operations, is a major surgery with significant morbidity and mortality. The pancreatico-enteric anastomosis has been the Achilles' heel of this operation. Adequate nutritional support, reduction of invasiveness, shorter operation times, combined regional/general anesthesia, and targetcontrolled fluid management are options for reducing postoperative morbidity. In recent decades, diagnostic modalities and the surgical and palliative treatments of PC have clearly progressed, although the overall prognosis has barely changed. The management of patient affected by PC is complex and requires exepertise in many fields. Multidisciplinary teams are necessary to optimize the overall care. The anesthesiologist plays a crucial role in the perioperative management of such patients and for patient with unresectable PC (anesthesia and analgesia). Careful patient selection, individualized preoperative evaluation and optimization go a long way in improving the short-term and long-term outcomes of these patients. In the future new protocols are necessary for pain control, adjuvant strategies, palliative measures in patients with pancreatic cancer.

\section{References}

Baum, J.A. (2004). The carrier gas in anaesthesia: nitrous oxide/oxygen, medical air/oxygen and pure oxygen. Curr Opin Anaesthesiol Vol. 17, No. 6, pp. 513-6, ISSN 0952-7907

Bluman, L.G., Mosca, L., Newman, N. \& Simon, D.G. (1998). Preoperative smoking habits and postoperative pulmonary complications. Chest, Vol. 113, pp. 883-9, ISSN 0012-3692

Buchler, M.W. et al. (2003). Changes in morbidity after pancreatic resection : toward the end of completion pancreatectomy. Arch Surg, Vol. 138,No. 12, pp. 1310-1314, ISSN 0004-0010

Chiu, J.W.\& White, P.F. (2000). The pharmacoeconomics of neuromuscular blocking drugs. J Anaesth, Vol.90, pp. S19-S23, ISSN 0003-2999

Clement, S., Braithwaite, S.S., Magee, M.F., et al. (2004). Management of diabetes and hyperglycemia in hospitals. Diabetes Care, Vol. 27, pp. 553-597, ISSN 0149-5992

Coursin, D.B., Connery, L.E. \& Ketzler, J.T.(2004). Perioperative diabetic and hyperglycemic management issues. Crit Care Med, Vol. 32, pp. S116-S125, ISSN 0090-3493

Davies, R.G., Myles, P.S. \& Graham, J.M. (2006). A comparison of the analgesic efficacy and site effects of paravertebral epidural blockade for thoracotomy- a systematic 
review and meta-analysis of randomized trials. Br j Anaesth, Vol. 96, No. 4, pp. 418-26, ISSN 0007-0912

Delbeke D., Rose, D.M., Chapman, W.C., Pinson, C.W., Wright, J.K., Beauchamp, R.D., Shyr Y. \& Learch, S.D. (1999). Optimal interpretation of FDG PET in the diagnosis, staging and management of pancreatic carcinoma. J Nucl Med, Vol. 40, No. 11, pp. 1784-1791, ISSN 0161-5505

Dershwitz, M., Hoke, J.F., Rosow, C.E., Michalowski, P., Connors, P.M., Muir, K.T et al. (1996). Pharmacokinetics and pharmacodynamics of remifentanil in volunteer subjects with severe liver disease. Anesthesiology, Vol. 84, No.4, pp. 812-20, ISSN 0003-3022

Fotiadis, R.J., Badvie, S., Weston, M.D. \& Allen-Mersh T.G. (2004). Epidural analgesia in gastrointestinal surgery. British Journal of Surgery, Vol. 91, No.7, pp. 828-841, ISSN 0007-1323

Furnary, A.P., Gao, G., Grunkemeier, G.L. et al.( 2003). Continuous insulin infusion reduces mortality in patients with diabetes undergoing coronary artery bypass grafting. $J$ Thorac Cardiovasc Surg,Vol. 125, No. 5, pp. 1007-1021, ISSN 0022-5223

Gass, G.D. \& Olsen, G.N. (1986). Preoperative pulmonary function testing to predict postoperative morbidity and mortality. Chest, Vol. 89, No. 1, pp. 127-35, ISSN 0012-3692

Ghaferi, A.A., Birkmeyer, J.D. \& Dimik, J.B. (2009). Variation in hospital mortality associated with inpatient surgery. N Engl J Med Vol. 361, No. 14, pp. 1368-75, ISSN 1533-4406

Gibbs, J., Cull,W., Henderson,W., Daley, J., Hur, K. \& Khuri, S.F.(1999). Preoperative serum albumin level as a predictor of operative mortality and morbidity : results from the National VA Surgical Risk Study. Arch Surg, Vol.134, No. 1, pp.36-42, ISSN 0004-0010

Giménez, A., Martínez-Noguera, A., Donoso, L., Catalá, E. \& Serra, R.(1993). Percutaneous neurolysis of the celiac plexus via the anterior approach with sonographic guidance. AJR Am J Roentgenol, Vol. 161, No. 5,pp. 1061-3, ISSN 0361-803X

Gogarten, W., Vandermeulen, E., Van Aken, H., Kozek, S., Van Llau, J. \& Samama, C.M. (2010). Regional anaesthesia and antithrombotic agents: recommendations of the European Society of Anaesthesiology. Eur J Anaesthesiol, Vol. 27, No. 12, pp. 9991015, ISSN 0265-0215

Goldberg, P.A., Siegel, M.D., Sherwin, R.S., et al. (2004). Implementation of a safe and effective insulin infusion protocol in a medical intensive care unit. Diabetes Care, Vol. 27, No. 2, pp. 461-467, ISSN 0149-5992

Gullo, L., Pezzilli, R. \& Morselli-Labate, A.M. (1994). Diabetes and the risk of pancreatic cancer. N Engl J Med, Vol. 331, No. 2, pp. 81-84, ISSN 0028-4793

Hecker K, Baumert, J.H., Horn, N. \& Rossaint, R. (2004). Xenon, a modern anaesthesia gas. Minerva Anestesiol, Vol.70, No. 5, pp. 255-60, ISSN 0375-9393

Henderson, K.A., Raj, N. \& Hall, J.E. (2002). The use of nitrous oxide in anaesthetic practice: a questionnaire survey. Anaesthesia, Vol. 57, No. 12, pp. 1155-8, ISSN 0003-2409

Inoue, K. et al. (2002). Spontaneous resolution of epidural hematoma after continuous epidural analgesia in a patient without bleeding tendency. Anesthesiology, Vol. 97, No. 3, pp. 735-7, ISSN 0003-3022 
Jemal A. et al. (2009). Cancer statistics, 2009.CA Cancer J Clin, Vol. 59, No. 4, pp. 225-249, ISSN 0007-9235

Jiang, W.G .\& Puntis MC. (1997). Immune dysfunction in patients with obstructive jaundice, mediators and implications for treatments. HPB Surg, Vol.10, No. 3, pp. 129-42, ISSN 0894-8569

Karmaker, M.K. (2001). Thoracic paravertebral block. Anesthesiology, Vol. 95, No. 3, pp. 77180, ISSN 0003-3022

Koretz, R.L., Lipman,T.O. \& Klein, S. (2001). AGA technical review on parenteral nutrition. Gastroenterology, Vol. 121, No. 4, pp. 970-1001, ISSN 0016-5085

Kullavanijaya, P., Treeprasertsuk, S., Thong-Nham, D., Kladcharoen, N., Mahachai, V. \& Suwanagool, P. (2001). Adenocarcinoma of the pancreas: the clinical experience of 45 histopathologically proven patients, a 6 year study. J Med Assoc Thai, Vol. 84, No 5, pp. 640-647, ISSN 0125-2208

Kumamoto, e., Mizuta, K. \& Fujita, T. (2011). Opiod actions in primary- afferent fibersinvolvement in analgesia and anestesia. Pharmaceuticals, Vol. 4, (January 2011), pp. 343-365, ISSN 1424-8247

Lawrence, V.A., Dhanda, R., Hilsenbeck, S.G. \& Page, P.G. (1996). Risk of pulmonary omplications after elective abdominal surgery. Chest, Vol. 110, No.3, pp. 744-50, ISSN 0012-3692

Lynch, S.M., Vrieling, A., Lubin, J.H., Kraft, P., Mendelson, J.B., Hartge, P., Canzian, F., Steplowski, E., Arslan, A.A., Gross,M.,Helzlsouer, K., Jacobs,E.J., La Croix,A., Petersen, G., Zheng, W., Albanes,D., Amundadottir, L., Bingham, S.A., Boffetta, P., Boutron-Ruault, M.C., Chanock, S.J., Clipp,S., Hoover, R.N., Jacobs, K. et al. (2009). Cigarette smoking and pancreatic cancer : a pooled analysis from the pancreatic cancer cohort consortium. Am J Epidemiol Vol. 170, No. 4,pp. 403-413, ISSN 0002-9262

Macias, A., Monedero, P., Adame, M., Torre, T., Fidalgo, I. \& Hidalgo, F. (2002). A randomized, double-blinded comparison of thoracic epidural ropivacaine, ropivacaine/ fentanyl, or bupivacaine / fentanyl for postthoracotomy analgesia. Anesth Analg, Vol. 95, No. 5, pp. 1344-50, ISSN 0003-2999

Miaskowski, C. (2005). Patient-controlled modalities for acute postoperative pain management. J Perianesth Nurs,Vol. 20, No. 4,pp. 255-67, ISSN 1089-9472

Murphy, G.S. \& Szokol, J.W. (2004). Monitoring neuromuscular blockade. Int Anesthesiol Clin, Vol.42, No.2, pp.25-40, ISSN 0020-5907

Myles, P.S., Iacono, G.A., Hunt, J.O., Fletcher, H., Morris, J., McIlory, D. \& Fritschi, L. (2002). Risk of respiratory complications and wound infection in patients undergoing ambulatory surgery : smokers versus nonsmokers. Anesthesiology, Vol. 97, No. 4, pp. 842-7, ISSN 0003-3022

Nussmeier, N.A., Whelton, A.A., Brown, M..T, Joshi, G.P., Langford, R.M., Singla, N.K., Boye, M.E. \& Verburg, K.M (2006). Anesthesiology,Vol. 104, No. 3, pp. 255-67, ISSN 0003-3022

Neugut, A.I., Ahsan, H. \& Robinson, E. (1995). Pancreas cancer as a second primary malignancy. A population- based study. Cancer, Vol. 76, No. 4, pp. 589-592, ISSN 0008-543X

Panousis,P., Heller, A.R., Koch, T. \& Litz, R. (2009). Epidural ropivacaine concentrations for intraoperative analgesia during major upper abdominal surgery : A prospective, 
randomized, double-blinded, placebo-controlled study. Anesthesia $\mathcal{E}$ analgesia, Vol.108, No. 6, (June 2009), pp. 1971-6, ISSN 0003-2999

Pearce, A.C. \& Jones, R.M. (1984). Smoking and anesthesia : preoperative abstinence and perioperative morbidity. Anesthesiology, Vol. 61, No. 5, pp. 576-84, ISSN 0003-3022

Permet, J., Ihse, I., Jorfeldt, L., von Schenck H et al. (1993). Pancreatic cancer is associated with impaired glucose metabolism. Eur J Surg, Vol. 159, No. 2, pp. 101-107, ISSN $1102-4151$

Puli, S.R. et al. (2009). US-guided celiac plexus neurolysis for pain due to chronic pancreatitis or pancreatic cancer pain: A meta-analysis and systematic review. Digestive Diseases Science, Vol. 54, No. 11, pp. 2330-7, ISSN 0163-2116

Riall, T.S., Reddy, D.M., Nelson, W.H. \& Goodwin, J.S. (2008). The effect of age on shortterm outcomes after pancreatic resection : a population-based study. Ann Surg, Vol. 248, No. 3, pp. 459-67, ISSN 0003-4932

Rehman, H.U. \& Mohammed, K. (2003). Perioperative management of diabetic patients. Curr Surg, Vol.60, No. 6, pp. 607-611, ISSN 0149-7944

Shaib Y.H., Davila J.A. \& El-Serag H.B. (2006). The epidemiology of pancreatic cancer in the United States: changes below the surface. Aliment pharmacol Ther, Vol. 24, No. 1, pp. 87-94, ISSN 0269-2813

Skilton, R.W.H. \& Justice, W. (1998). Epidural hematoma following anticoagulant treatment in a patient with an indwelling epidural catheter. Anesthesia, Vol. 53, No. 7, pp. 691-701, ISSN 0003-2409

Staatas, P.S. et al. (2001). The effects of alcohol celiac block, pain and mood on longevity in patients with unresectable pancreatic pain: A double-blind, randomized, placebocontrolled study. Pain Medicine, Vol. 2, No. 1, pp. 28-34, ISSN 1526-2375

Tilleman, E.H., Busch, O.R., Bemelman, W.A., van Gulik, T.M., Obertop, H. \& Gouma, D.J. (2004). Diagnostic laparoscopy in staging pancreatic carcinoma: Developments during the past decade. J Hepatobiliary Pancreat Surg, Vol. 11, No. 1, pp. 11-16, ISSN 0944-1166

Treiman, G.S., Treiman RL, Foran RF et al. (1994). The influence of diabetes mellitus on the risk of abdominal aortic surgery. Am Surg, Vol. 60, No. 6, pp. 436-40, ISSN 00031348

Tryba, M. (1998). European practice guidelines: Thromboembolism prophylaxis and regional anesthesia. Reg Anesth Pain Med, Vol. 23 (Suppl. 2), pp. 178-82, ISSN 1098-7339

Van der Gaag, N.A., Kloek, J.J., de Castro, S.M., Busch, O.R., van Gulik, T.M. \& Gouma, D.J. (2009). Preoperative biliary drainage in patients with obstructive jaundice : history and current status. J Gastrointest Surg, Vol. 13, No. 4, pp. 814-20, ISSN 1091-255X

Van der Gaag, N.A., Rauws, E.A.J., van Eijck, H.J., Bruno, M.J., van derd Harst, E., Kubben, F.J., Gerritsen, J., Greve, J.W., Gerhards, M.F. et al. (2010). Preoperative biliary drainage for cancer of the head of the pancreas. $N$ Engl J Med, Vol. 362, No. 2, pp. 129-37, ISSN 0028-4793

Van Lier, F., Van der Geest, P., Hoeks, S., Van Gestel, Y., Hol, J., Sin, D., Stolker, R.J. \& Poldermans, D. (2011). Epidural analgesia is associated with improved health outcomes of surgical patients with chronic obstructive pulmonary disease. Anesthesiology, Vol. 115, No. 2, pp. 315-21, ISSN 0003-3022 
Vandermeulen, E.P., Van Haken, H. \& Vermylen, J. (1994). Anticoagulants and spinalepidural anesthesia. Anesth Analg, Vol. 79,No. 6, pp. 1165-77, ISSN 0003-2999

Verhofstad, H.J. \& Hendriks, T. (1996). Complete prevention of impaired anastomotic healing in diabetic rats requires preoperative blood glucose control. Br J Surg, Vol. 83, No. 12, pp. 1717-21, ISSN 0007-1323

Zacharias, A.Z. \& Habib, R.H. (1996). Factors predisposing to median sternotomy complications. Chest, Vol. 110, No. 5, pp. 1173-8, ISSN 0012-3692

WHO (2008). Scoping document for WHO treatment guideline on pain related to cancer, HIV and other progressive life-threatening illnesess in adult adopted in WHO steering group on pain guidelines, 14 October 2008. WHO Steereing Group on Pain Guidelines 


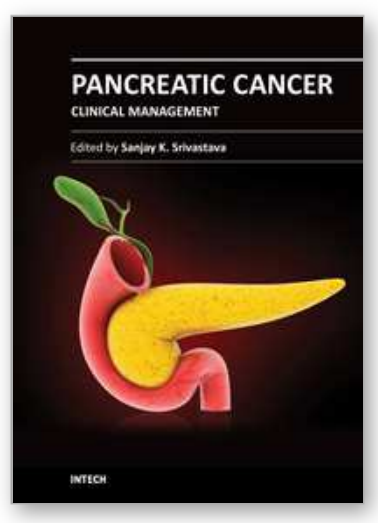

\author{
Pancreatic Cancer - Clinical Management \\ Edited by Prof. Sanjay Srivastava
}

ISBN 978-953-51-0394-3

Hard cover, 312 pages

Publisher InTech

Published online 28, March, 2012

Published in print edition March, 2012

This book covers pancreatic cancer risk factors, treatment and clinical procedures. It provides an outline of pancreatic cancer genetic risk factors, biomarkers and systems biology for the better understanding of disease. As pancreatic cancer suffers from lack of early diagnosis or prognosis markers, this book encompasses stem cell and genetic makers to identify the disease in early stages. The book uncovers the rationale and effectiveness of monotherapy and combination therapy in combating the devastating disease. As immunotherapy is emerging as an attractive approach to cease pancreatic cancer progression, the present book covers various aspects of immunotherapy including innate, adaptive, active, passive and bacterial approaches. Management of anesthesia during surgery and pain after surgery has been discussed. Book also takes the reader through the role of endoscopy and fine needle guided biopsies in diagnosing and observing the disease progression.

\title{
How to reference
}

In order to correctly reference this scholarly work, feel free to copy and paste the following:

Maurizio Marandola and Alida Albante (2012). Anesthesia and Pain Management: Techniques and Practice, Pancreatic Cancer - Clinical Management, Prof. Sanjay Srivastava (Ed.), ISBN: 978-953-51-0394-3, InTech, Available from: http://www.intechopen.com/books/pancreatic-cancer-clinical-management/anaesthesia-andpain-management-techniques-and-practice

\section{INTECH}

open science | open minds

\section{InTech Europe}

University Campus STeP Ri

Slavka Krautzeka 83/A

51000 Rijeka, Croatia

Phone: +385 (51) 770447

Fax: +385 (51) 686166

www.intechopen.com

\section{InTech China}

Unit 405, Office Block, Hotel Equatorial Shanghai

No.65, Yan An Road (West), Shanghai, 200040, China

中国上海市延安西路65号上海国际贵都大饭店办公楼 405 单元

Phone: +86-21-62489820

Fax: $+86-21-62489821$ 
(C) 2012 The Author(s). Licensee IntechOpen. This is an open access article distributed under the terms of the Creative Commons Attribution 3.0 License, which permits unrestricted use, distribution, and reproduction in any medium, provided the original work is properly cited. 